\title{
INVERSE PROBLEM FOR SOBOLEV TYPE EQUATION OF THE SECOND ORDER
}

\author{
A.A. Zamyshlyaeva, A.S. Muravyev \\ South Ural State University, Chelyabinsk, Russian Federation \\ E-mail: zamyshliaevaaa@susu.ru
}

The paper deals with the inverse problem for the Sobolev type equation of the second order in Banach spaces. The introduction contains a problem statement and the historiography of Sobolev type equations. The second part includes preliminary information based on the results of the theory of higher-order Sobolev type equations. In the third part the initial problem is reduced to the inverse regular and singular problems. A theorem of unique solvability of regular problem is formulated and proved. Using the results of the third part, the solution for the singular problem is obtained in the fourth part. The sum of regular and singular solutions is a solution to the original problem, thus a theorem on the unique solvability of the inverse problem for Sobolev type equation of the second order is stated and proved.

Keywords: Sobolev type equation of the second order; inverse problem; a unique solvability theorem.

\section{Introduction}

Let $U, F, Y$ be Banach spaces, operator $\chi:[0, T] \rightarrow L(Y ; F)$, functions $M:[0, T] \rightarrow F$, $\Psi:[0, T] \rightarrow Y$, operator $C \in L(U ; F)$. Consider the following problem

$$
\begin{gathered}
A \ddot{v}(t)=B_{1} \dot{v}(t)+B_{0} v(t)+\chi(t) q(t)+M(t), t \in[0, T], \\
v(0)=v_{0}, \dot{v}(0)=v_{1}, \\
C v(t)=\Psi(t)
\end{gathered}
$$

The inverse is a problem of finding a pair of functions $v \in C^{2}([0, T] ; U)$ and $q \in C^{2}([0, T] ; Y)$ from relations (1)-(3). Note that (1) is a special case of equation

$$
A v^{(n)}(t)=B_{n-1} v^{(n-1)}(t)+\ldots+B_{0} v(t)+f(t),
$$

which is called the higher order Sobolev type equation. Such operator-differential equations were firstly studied in [1, 2], and in more detail in [3]. Inverse Problems for Sobolev type equations, and other nonclassical equations of mathematical physics were studied earlier in [4-6], and the inverse problem for the first-order equation was considered in [7].

Equations nonsolvable with respect to the highest derivative were firstly studied in 1885 in the works of Poincaré. Often they were associated with studies of specific equations of hydrodynamics. Considerable interest in equations of this kind appeared in connection with the results C.W. Oseen, J. Leray, F.K.G. Odqvist and J. Schauder, E. Hopf and studies of S.L. Sobolev on the problem of small oscillations of a rotating fluid. This series of works initiated further research of equations nonsolvable with respect to the highest derivative. Thus, it was the basis for a new direction, which was originally developed by the disciples of S.L. Sobolev. After the first studies of S.L. Sobolev, I.G. Petrovsky spoke of need to investigate general differential equations and general differential systems that are not solvable with respect to highest derivative in time (such systems are called not of the Kovalevskaya type systems). In literature such equations and their specific interpretations are often called Sobolev type equations, saluting the founder.

The first attempt to study the phase space for the higher order equations was made in $[8,9]$. In these works according to the ideology of M.V. Keldysh equation (4) was reduced to the equivalent first-order Sobolev-type equation, which has been studied by methods described in [10]. However, it should be 


\section{Математика}

noted that the inverse reduction lead to a very complex algorithm of construction of the phase space. Moreover, it was not shown that all the initial values were lying in the same phase space.

Inverse problems often arise in different fields of science, particularly in the description of the internal characteristics of the medium in which the physical or chemical processes take place; when the results of observations of these processes are available for the measurement. The great interest to inverse problems appeared at the junction of the 19th and 20th centuries, particularly in geophysics. There was a pressing question: is it possible by the picture of movement of seismic wave fronts from the various earthquakes on the Earth's surface, to find the velocity of propagation of seismic waves in the Earth? There was formulated an inverse kinematic problem, firstly considered by the German geophysicists E. Wiechert and G. Herglotz. At the same time there arose another inverse problem in the potential theory. The studies of inverse problems in the potential theory in various productions were held by in V.N. Strakhov, A.N. Tikhonov, M.M. Lavrent'ev, V.K. Ivanov, A.I. Prilepko as well as their disciples. The inverse problems for dynamic reconstruction of the parameters of control systems and associated illposed problems were investigated in scientific schools of V.K. Ivanov, N.N. Krasovsky and others. In addition, there were studied inverse problems of electromagnetic intelligence, quantum scattering theory, and many others. Nowadays there appear new formulations of inverse problems and new results concerning their solvability.

\section{Preliminary information}

We use results of the theory of higher-order Sobolev type equations. Proofs of these results can be found in [2].

Definition 1. The sets

$$
\rho^{A}(\vec{B})=\left\{\mu \in C:\left(\mu^{n} A-\mu^{n-1} B_{n-1}-\ldots-\mu B_{1}-B_{0}\right)^{-1} \in L(F, U)\right\}
$$

and $\sigma^{A}(\vec{B})=\bar{C} \backslash \rho^{A}(\vec{B})$ are called an A-resolvent set of and an A-spectrum of pencil $\vec{B}$.

Definition 2. The operator-valued function of a complex variable $R_{\mu}^{A}(\vec{B})=\left(\mu^{n} A-\mu^{n-1} B_{n-1}-\ldots-\mu B_{1}-B_{0}\right)^{-1}$ with domain $\rho^{A}(\vec{B})$ is called an A-resolvent of pencil $\vec{B}$.

Definition 3. The pencil $\vec{B}$ is called polynomially bounded with respect to the operator $A$ (polynomially A-bounded), if

$$
\exists a \in R_{+} \forall \mu \in C(|\mu|>a) \Rightarrow\left(R_{\mu}^{A}(\vec{B}) \notin L(F ; U)\right) .
$$

For further considerations we require fulfillment of additional conditions

$$
\int_{\gamma} \mu^{k} R_{\mu}^{A}(\vec{B}) d \mu \equiv 0, k=0,1
$$

where the contour $\gamma=\{\mu \in C:|\mu|=r>a\}$.

Lemma 1. Let the pencil $\vec{B}$ be polynomially A-bounded and condition (A) be fulfilled. Then the operators $P \in L(U)$ and $Q \in L(F)$, defined by formulas

are projectors.

$$
P=\frac{1}{2 \pi i} \int_{\gamma} R_{\mu}^{A}(\vec{B}) \mu A d \mu, Q=\frac{1}{2 \pi i} \int_{\gamma} \mu A R_{\mu}^{A}(\vec{B}) d \mu,
$$

Theorem 1. Let the pencil $\vec{B}$ be polynomially A-bounded and condition (A) be fulfilled. Then the actions of operators split:

$$
\begin{array}{ll}
A^{k} \in L\left(U^{k} ; F^{k}\right), & k=0,1 ; \\
B_{l}^{k} \in L\left(U^{k} ; F^{k}\right), & k=0,1, l=0,1 ;
\end{array}
$$

(iii) there exists an operator $\left(A^{1}\right)^{-1} \in L\left(F^{1} ; U^{1}\right)$,

(iv) there exists an operator $\left(B_{0}^{0}\right)^{-1} \in L\left(F^{0} ; U^{0}\right)$.

Definition 4. Define a family of operators $\left\{K_{q}^{1}, K_{q}^{2}\right\}$ in the following way:

$$
K_{1}^{1}=H_{0}, \quad K_{1}^{2}=-H_{1}, \quad K_{q+1}^{1}=K_{q}^{2} H_{0}, \quad K_{q+1}^{2}=K_{q}^{1}-K_{q}^{2} H_{1},
$$


where operators $H_{0}=\left(B_{0}^{0}\right)^{-1} A^{0}, H_{1}=\left(B_{0}^{0}\right)^{-1} B_{1}^{0}$.

Definition 5. The point $\infty$ is called

(i) a removable singular point of the $A$ - resolvent of pencil $\vec{B}$, if $K_{1}^{1} \equiv O, K_{1}^{2} \equiv O$;

(ii) a pole of order $p \in N$ of the $A$ - resolvent of pencil $\vec{B}$, if $K_{p}^{1} \neq O, K_{1}^{2} \neq O$, but $K_{p+1}^{1} \equiv O, K_{p+1}^{2} \equiv O$.

an essential singularity of the $A$ - resolvent of pencil $\vec{B}$, if $K_{k}^{2} \neq O, k \in N$.

\section{Reduction of initial inverse problem}

Let the pencil $\vec{B}=\left(B_{0}, B_{1}\right) \quad$ be polynomially A-bounded, $U^{0} \in \operatorname{ker} C$. Denote $v(t)=P v(t)+(I-P) v(t)$. Then $P v(t)=u(t),(I-Q) v(t)=w(t)$. Then by Lemma 1 and Theorem 1 , problem (1)-(3) is equivalent to the problem of finding functions $u \in C^{2}\left([0, T] ; U^{1}\right)$, $w \in C^{2}\left([0, T] ; U^{0}\right), q \in C^{2}([0, T] ; Y)$ from

$$
\begin{gathered}
\ddot{u}(t)=S_{1} \dot{u}(t)+S_{0} u(t)+A_{1}^{-1} Q \chi(t) q(t)+A_{1}^{-1} Q M(t), t \in[0, T], \\
u(0)=v_{0}^{1}, \dot{u}(0)=v_{1}^{1} . \\
C u(t)=C v(t)=\Psi(t), t \in[0, T], \\
H_{0} \ddot{w}(t)=H_{1} \dot{w}(t)+w(t)+\left(B_{0}^{0}\right)^{-1}(I-Q) \chi(t) q(t)+\left(B_{0}^{0}\right)^{-1}(I-Q) M(t), \quad t \in[0, T], \\
w(0)=v_{0}^{0}, \dot{w}(0)=v_{1}^{0},
\end{gathered}
$$

\section{Smooth solutions of regular problem}

Inverse problem (5)-(7) is called regular. The direct problem (8), (9) with given function $q$ is called singular. For convenience, we rewrite regular problem as follows:

$$
\begin{gathered}
\ddot{u}(t)=S_{1} \dot{u}(t)+S_{0} u(t)+\Phi(t) q(t)+F(t), t \in[0, T], \\
u(0)=u_{0}, \dot{u}(0)=u_{1}, \\
C u(t)=\Psi(t)
\end{gathered}
$$

In order to obtain a solution of (8), (9), we need to require the smoothness of class $C^{p+2}([0, T] ; Y)$ of solution $q$ of the regular inverse problem. Further we find a sufficient condition for the existence of a smooth solution $q \in C^{p+2}([0, T] ; Y)$.

Lemma 2. Let $n \in N, S \in C^{n}([0, T] ; L(X)), g \in C^{n}([0, T] ; X)$. Then

$$
\left(\int_{\gamma} S(t-s) g(s) d s\right)^{(n)}=\sum_{i=0}^{n-1} S^{(i)}(t) g^{(n-1-i)}(0)+\int_{0}^{t} S(t-s) g^{(n)}(s) d s .
$$

Proof. Let us prove formula (13) for $n=1$ :

$$
\begin{gathered}
\left(\int_{0}^{t} S(t-s) g(s) d s\right)^{\prime}=S(0) g(t)+\int_{0}^{t} \frac{d}{d t} S(t-s) g(s) d s=S(0) g(t)+\int_{0}^{t}\left[\frac{d}{d s} S(t-s)\right] g(s) d s= \\
=S(t) g(0)+\int_{0}^{t} S(t-s) g^{\prime}(s) d s .
\end{gathered}
$$

Assume that for $n=m$ equality (13) holds and prove that it is satisfied with $n=m+1$

$$
\begin{gathered}
\left(\int_{0}^{t} S(t-s) g(s) d s\right)^{(m+1)}=\frac{d}{d t}\left[\sum_{i=0}^{m-1} S^{(i)}(t) g^{(m-1-i)}(0)+\int_{0}^{t} S(t-s) g^{(m)}(s) d s\right]=\sum_{i=1}^{m} S^{(i)}(t) g^{(m-1-i)}(0)+ \\
+\int_{0}^{t}\left[\frac{d}{d s} S(t-s)\right] g^{(m)}(s) d s=\sum_{i=0}^{m} S^{(i)}(t) g^{(m-i)}(0)+\int_{0}^{t} S(t-s) g^{(m+1)}(s) d s .
\end{gathered}
$$




\section{Математика}

The lemma is proved.

Theorem 2. Suppose that the pencil $\vec{S}=\left(S_{0}, S_{1}\right)$ is polynomially bounded, $C \in L(X ; Y), \quad p \in N_{0}$, $\Phi \in C^{p+2}([0, T] ; L(Y, X)), \quad F \in C^{p+2}([0, T] ; X), k=0,1, \ldots, p, \Psi \in C^{p+2}([0, T] ; Y)$, for all $t \in[0, T]$ the operator $C \Phi(t)$ is invertible, $(C \Phi)^{-1} \in C^{p+2}([0, T] ; L(Y))$ and condition $C u_{0}=\Psi(0)$ is fulfilled. Then there exists a unique solution $u \in C^{p+2}([0, T] ; X), q \in C^{p+2}([0, T] ; Y)$ of the inverse problem (10)-(12).

Proof. Before proceeding to the proof of the theorem denote $S(t)=\frac{1}{2 \pi i} \int_{\gamma}\left(\mu^{2} I-\mu S_{1}-S_{0}\right)^{-1} \mu^{2} e^{\mu t} d \mu$. According to theorem 6.2.3 [11], the searched function $q$ is a solution of equation

$$
q(t)=q_{0}(t)+R(t) \int_{0}^{t} C S(t-s) g(s) d s
$$

where $q_{0}(t)=R(t)\left(\Psi^{\prime}(t)-C S(t) u_{0}-C \int_{0}^{t} S(t-s) F^{\prime}(s) d s-C F(t)\right), \quad R(t)=(-C \Phi(t))^{-1}$.

Prove using the results of Lemma 2 that function $q \in C^{p+2}([0, T], Y)$.

$$
\begin{aligned}
& q^{\prime}(t)=q_{0}^{\prime}(t)+R^{\prime}(t) \int_{0}^{t} C S(t-s) g(s) d s+R(t) C S(0) g(t)+R(t) \int_{0}^{t} C S^{\prime}(t-s) g(s) d s, \\
& q^{\prime \prime}(t)=q_{0}^{\prime \prime}(t)+R^{\prime \prime}(t) \int_{0}^{t} C S(t-s) g(s) d s+R^{\prime}(t) C S(0) g(t)+R^{\prime}(t) C S(0) g(t)+ \\
& +R(t) C S(0) g^{\prime}(t)+R(t) C S^{\prime}(0) g(t)+R(t) \int_{0}^{t} C S^{\prime \prime}(t-s) g(s) d s+R^{\prime}(t) \int_{0}^{t} C S^{\prime}(t-s) g(s) d s, \\
& q^{\prime \prime \prime}(t)=q_{0}^{\prime \prime \prime}(t)+R^{\prime \prime \prime}(t) \int_{0}^{t} C S(t-s) g(s) d s+R^{\prime \prime}(t) C S(0) g(t)+ \\
& +R^{\prime \prime}(t) \int_{0}^{t} C S^{\prime}(t-s) g(s) d s+2 R^{\prime \prime}(t) C S(0) g(t)+2 R^{\prime}(t) C S(0) g^{\prime}(t)+R^{\prime}(t) C S(0) g^{\prime}(t)+ \\
& +R(t) C S(0) g^{\prime \prime}(t)+R^{\prime}(t) C S^{\prime}(0) g(t)+R(t) C S^{\prime}(0) g^{\prime}(t)+R^{\prime}(t) \int_{0}^{t} C S^{\prime \prime}(t-s) g(s) d s+ \\
& +R^{\prime}(t) C S^{\prime}(0) g(t)+R^{\prime}(t) \int_{0}^{t} C S^{\prime \prime}(t-s) g(s) d s=q_{0}^{\prime \prime \prime}(t)+R(t) C\left(S(t) g^{\prime \prime}(0)+S^{\prime}(t) g^{\prime}(0)+S^{\prime \prime}(t) g(0)\right)+ \\
& +R(t) C \int_{0}^{t} S(t-s) g^{\prime \prime \prime}(s) d s+3 R^{\prime}(t) C\left(S(t) g^{\prime}(0)+S^{\prime}(t) g(0)+\int_{0}^{t} S(t-s) g^{\prime \prime}(s) d s\right)+ \\
& +3 R^{\prime}(t) C\left(S(t) g(0)+\int_{0}^{t} S(t-s) g^{\prime}(s) d s\right)+R^{\prime \prime \prime}(t) C \int_{0}^{t} S(t-s) g(s) d s . \\
& q^{(n)}(t)=q_{0}^{(n)}(t)+\sum_{k=0}^{n-1} \sum_{i=0}^{k} C_{n}^{i} C R^{(i)}(t) S^{(n-1-k)}(t) g^{(n-1-i)}(0)+\sum_{i=0}^{n} C_{n}^{i} C R^{(i)}(t) \int_{0}^{t} S(t-s) g^{(n-i)}(s) d s .
\end{aligned}
$$

Derivatives

$$
q_{0}^{(n)}(t)=\sum_{i=0}^{n} C_{n}^{i} R^{(i)}(t)\left(\Psi^{(n+1)}(t)-C S^{(n)}(t) u_{0}+C \sum_{k=0}^{i-1} S^{(k)}(t) F^{(i-1-k)}(0)+C \int_{0}^{t} S(t-s) F^{(i)}(s) d s-C F^{(n)}(t)\right)
$$

exist because of the conditions of this theorem for $n=0,1, \ldots, p+1$. 
Denote $r_{0}=q_{0}(0)$ and for $n=0,1, \ldots, p+1$ consistently define values

$$
r_{n}=q_{0}^{(n)}(0)+\sum_{k=0}^{n-1} \sum_{i=0}^{k} C_{n}^{i} C R^{(i)}(0) S^{(n-1-k)}(t) S^{(n-1-i)}(0) \sum_{l=0}^{n-1-i} \Phi^{(l)}(0) r_{l} .
$$

Consider the system of integral equations

$$
\begin{gathered}
\tilde{q}_{0}(t)=q_{0}(t)+R(t) \int_{0}^{t} C S(t-s) \Phi(s) \tilde{q}_{0}(s) d s, \\
\tilde{q}^{(n)}(t)=q_{0}^{(n)}(t)+\sum_{k=0}^{n-1} \sum_{i=0}^{k} C_{n}^{i} C R^{(i)}(t) S^{(n-1-k)}(t) \sum_{l=0}^{n-1-i} \Phi^{(l)}(0) r_{l}+ \\
+\sum_{i=0}^{n} C_{n}^{i} C R^{(i)}(t) \int_{0}^{t} S(t-s) \sum_{l=0}^{n-i} C_{n}^{i} \Phi^{(l)}(0) q_{n-i-l}(s) d s, \text { при } n=1, \ldots, p+1 .
\end{gathered}
$$

System (14) can be reduced to the Volterra equation of the second kind

$$
g(t)=g_{0}(t)+\int_{0}^{t} K(t, s) g(s) d s
$$

in the space $(C([0, T] ; Y))^{p+2}$ with matrix-operator function $K(t, s)$, defined in a triangle $\Delta=\left\{(t, s) \in R^{2}: 0 \leq t \leq T, 0 \leq s \leq t\right\}$. By the continuity of all elements of system (14), it has a unique solution. This solution is the limit of a sequence of approximations

$$
\begin{gathered}
\tilde{q}_{0, i}(t)=q_{0}(t)+R(t) \int_{0}^{t} C S(t-s) \Phi(s) \tilde{q}_{0, i-1}(s) d s, \\
\tilde{q}_{n, i}(t)=q_{0}^{(n)}(t)+\sum_{k=0}^{n-1} \sum_{i=0}^{k} C_{n}^{i} C R^{(i)}(t) S^{(n-1-k)}(t) \sum_{l=0}^{n-1-i} \Phi^{(l)}(0) r_{l}+ \\
+\sum_{i=0}^{n} C_{n}^{i} C R^{(i)}(t) \int_{0}^{t} S(t-s) \sum_{l=0}^{n-i} C_{n}^{i} \Phi^{(l)}(s) q_{n-i-l, i-1}(s) d s, \text { for } n=1, \ldots, p+1 .
\end{gathered}
$$

which uniformly on $[0, T]$ converges to $\tilde{q}_{n}, n=1, \ldots, p+1$ while $i \rightarrow \infty$. For an initial approximation we take $\tilde{q}_{n, 0} \equiv 0$, then $\tilde{q}_{n+1,0}=\tilde{q}_{n, 0}^{\prime}, n=0, \ldots, p$. In view of (15)

$$
\tilde{q}_{n, i}(0)=r_{n}, n=0, \ldots, p+1, i \in N .
$$

Suppose that for all $j=1, \ldots, i$ the equality $\tilde{q}_{n+1, j}(t)=\tilde{q}_{n, j}^{\prime}(t), n=0, \ldots, p$ is true. In this case, by Lemma 2 and (16),

$$
\begin{aligned}
& \frac{d}{d t}\left[\sum_{i=0}^{n} \sum_{l=0}^{n-i} C_{n}^{i} C R^{(i)}(t) \int_{0}^{t} S(t-s) C_{n-i}^{l} \Phi^{(l)}(s) q_{n-i-l, i}(s) d s\right]= \\
& =\sum_{i=0}^{n} \sum_{l=0}^{n-i} C_{n}^{i} C R^{(i+1)}(t) \int_{0}^{t} S(t-s) C_{n-i}^{l} \Phi^{(l)}(s) q_{n-i-l, i}(s) d s+ \\
& \quad+\sum_{i=0}^{n} \sum_{l=0}^{n-i} C_{n}^{i} C R^{(i)}(t) S(t) C_{n-i}^{l} \Phi^{(l)}(s) q_{n-i-l, i}(0)+ \\
& +\sum_{i=0}^{n} \sum_{l=0}^{n-i} C_{n}^{i} C R^{(i)}(t) \int_{0}^{t} S(t-s) C_{n-i}^{l} \Phi^{(l+1)}(s) q_{n-i-l, i}(s) d s+ \\
& +\sum_{i=0}^{n} \sum_{l=0}^{n-i} C_{n}^{i} C R^{(i)}(t) \int_{0}^{t} S(t-s) C_{n-i}^{l} \Phi^{(l)}(s) q_{n-i-l+1, i}(s) d s= \\
& =\sum_{i=0}^{n} \sum_{l=0}^{n-i} C_{n}^{i} C R^{(i)}(t) S(t) C_{n-i}^{l} \Phi^{(l+1)}(s) q_{n-i-l, i}(0)+
\end{aligned}
$$




$$
\begin{aligned}
& +\sum_{i=1}^{n+1} \sum_{l=0}^{n-i+1} C_{n}^{i} C R^{(i)}(t) \int_{0}^{t} S(t-s) C_{n-i}^{l} \Phi^{(l)}(s) q_{n-i-l+1, i}(s) d s+ \\
& +\sum_{i=0}^{n} \sum_{l=1}^{n-i+1} C_{n}^{i} C R^{(i)}(t) \int_{0}^{t} S(t-s) C_{n-i}^{l} \Phi^{(l)}(s) q_{n-i-l+1, i}(s) d s+ \\
& +\sum_{i=0}^{n} \sum_{l=0}^{n-i} C_{n}^{i} C R^{(i)}(t) \int_{0}^{t} S(t-s) C_{n-i}^{l} \Phi^{(l)}(s) q_{n-i-l+1, i}(s) d s= \\
& =\sum_{i=0}^{n} \sum_{l=0}^{n-i} C_{n}^{i} C R^{(i)}(t) S(t) C_{n-i}^{l} \Phi^{(l+1)}(s) q_{n-i-l, i}(0)+ \\
& +\sum_{i=0}^{n+1} \sum_{l=0}^{n-i+1} C_{n+1}^{i} C R^{(i)}(t) \int_{0}^{t} S(t-s) C_{n-i}^{l} \Phi^{(l)}(s) q_{n-i-l+1, i}(s) d s .
\end{aligned}
$$

Differentiate the second term:

$$
\begin{gathered}
\frac{d}{d t}\left[\sum_{k=0}^{n-1} \sum_{i=0}^{k} \sum_{l=0}^{n-1-i} C_{n}^{i} C R^{(i)}(t) S^{(n-1-k)}(t) \Phi^{(l)}(0) r_{l}\right]=\sum_{k=0}^{n-1} \sum_{i=0}^{k} \sum_{l=0}^{n-1-i} C_{n}^{i} C R^{(i+1)}(t) S^{(n-1-k)}(t) \Phi^{(l)}(0) r_{l}+ \\
+\sum_{k=0}^{n-1} \sum_{i=0}^{k} \sum_{l=0}^{n-1-i} C_{n}^{i} C R^{(i)}(t) S^{(n-k)}(t) \Phi^{(l)}(0) r_{l}=\sum_{k=1}^{n} \sum_{i=1}^{k} \sum_{l=0}^{n-1-i} C_{n}^{i} C R^{(i+1)}(t) S^{(n-k)}(t) \Phi^{(l)}(0) r_{l}+ \\
+\sum_{k=0}^{n+1} \sum_{i=1}^{k} \sum_{l=0}^{n-1-i} C_{n}^{i} C R^{(i+1)}(t) S^{(n-k)}(t) \Phi^{(l)}(0) r_{l}=\sum_{k=0}^{n} \sum_{i=1}^{k} \sum_{l=0}^{n-1-i} C_{n}^{i} C R^{(i)}(t) S^{(n-k)}(t) \Phi^{(l)}(0) r_{l}+ \\
+\sum_{i=1}^{n-1} \sum_{l=0}^{n-1-i} C_{n}^{i} C R^{(i)}(t) S(t) \Phi^{(l)}(0) r_{l}+\sum_{k=0}^{n} \sum_{l=0}^{n-1} C R(t) S(t) \Phi^{(l)}(0) r_{l}= \\
=\sum_{k=0}^{n} \sum_{i=1}^{k} \sum_{l=0}^{n-1-i} C_{n+1}^{i} C R^{(i)}(t) S^{(n-k)}(t) \Phi^{(l)}(0) r_{l}+\sum_{i=1}^{n} \sum_{l=0}^{n-1-i} C_{n}^{i} C R^{(i)}(t) S(t) \Phi^{(l)}(0) r_{l}+ \\
\quad+\sum_{k=1}^{n+1} \sum_{l=0}^{n-1} C R(t) S(t) \Phi^{(l)}(0) r_{l}-\sum_{i=1}^{n} \sum_{l=0}^{n-1-i} C_{n}^{i-1} C R^{(i)}(t) S(t) \Phi^{(l)}(0) r_{l}= \\
=\sum_{k=0}^{n+1} \sum_{i=0}^{k} \sum_{l=0}^{n-1-i} C_{n+1}^{i} C R^{(i)}(t) S^{(n-k)}(t) \Phi^{(l)}(0) r_{l}-\sum_{i=0}^{n} \sum_{l=0}^{n-i} C_{n}^{i} C R^{(i)}(t) S(t) \Phi^{(l)}(0) r_{l} .
\end{gathered}
$$

Differentiating (15), from (17) and (18) we obtain the equality $\tilde{q}_{n+1, i+1}(t)=\tilde{q}_{n, i+1}^{\prime}(t)$. Thus, the sequence $\tilde{q}_{0, i}$ converges to the function $\tilde{q}_{0}$ uniformly on $[0, T]$ when $i \rightarrow \infty$, and moreover $\tilde{q}_{0, i}^{\prime}=\tilde{q}_{1, i}$. Similarly prove equality $\tilde{q}_{n+1}(t)=\tilde{q}_{n}^{\prime}(t), n=1, \ldots, p$, consequently $\tilde{q}_{0}(t) \equiv q \in C^{p+2}([0, T] ; Y)$ and hence $q^{(n)}=\tilde{q}_{n}, n=1, \ldots, p+1$. So the function $u$ is $p+2$ times differentiable. This proves the theorem.

\section{The solvability of the initial problem}

Denote $\chi_{0}(t)=(I-Q) \chi(t), M_{0}(t)=(I-Q) M(t)$.

Lemma 3. Let the pencil $\vec{B}$ be polynomially A-bounded, condition (A) be fulfilled and $\infty$ be a pole of order $p \in N$ of the A-resolvent of pencil $\vec{B}$. Let $\chi_{0} \in C^{p+2}\left([0, T] ; F^{0}\right), M_{0} \in C^{p+2}\left([0, T] ; F^{0}\right)$ and initial conditions $w_{k}^{0} \in U^{0}$ satisfy $w_{k}^{0}=-\left.\sum_{q=0}^{p} K_{q}^{2}\left(B_{0}^{0}\right)^{-1} \frac{d^{q+k}}{d t^{q+k}}\left(\chi_{0}(t) q(t)+M_{0}(t)\right)\right|_{t=0}, k=0,1$. Then there exists a unique solution $w \in C^{2}\left([0, T] ; U^{0}\right)$ of problem (8), (9), which can be represented as

$$
w(t)=-\sum_{q=0}^{p} K_{q}^{2}\left(B_{0}^{0}\right)^{-1} \frac{d^{q}}{d t^{q}}\left(\chi_{0}(t) q(t)+M_{0}(t)\right) .
$$


Proof. Denote $\chi_{0}(t) q(t)+M_{0}(t)=f^{0}(t)$, in this case $w_{k}^{0}=-\sum_{q=0}^{p} K_{q}^{2}\left(B_{0}^{0}\right)^{-1} \frac{d^{q+k}}{d t^{q+k}} f^{0}(0), k=0,1$. Therefore all the conditions of Lemma 2.7.2 [2] hold. Thus there exists a unique solution $w(t)=-\sum_{q=0}^{p} K_{q}^{2}\left(B_{0}^{0}\right)^{-1} \frac{d^{q}}{d t^{q}}\left(f^{0}(t)\right)$ of (8), (9).

Theorem 3. Let the pencil $\vec{B}=\left(B_{0}, B_{1}\right)$ be polynomially A-bounded, condition (A) be fulfilled and $\infty$ be a pole of order $p \in N$ of the A-resolvent of pencil $\vec{B}$. Let the operator $C \in L(X ; Y), \operatorname{ker} C$ be not empty, $\chi_{0} \in C^{p+2}\left([0, T] ; F^{0}\right), \quad M_{0} \in C^{p+2}\left([0, T] ; F^{0}\right), \quad \Psi \in C^{p+2}([0, T] ; Y)$, for all $t \in[0, T]$ operator $C \chi(t)$ be invertible, $(C \chi)^{-1} \in C^{p+2}([0, T] ; L(Y))$ and condition $C v_{0}=\Psi(0)$ hold. Then there exists a unique solution $(v, q)$ of inverse problem (1)-(3), such that $v=u+w$, where $u \in C^{p+2}\left([0, T] ; U^{1}\right)$ and $q \in C^{p+2}([0, T] ; Y)$ are defined in Theorem 2, $w \in C^{2}\left([0, T] ; U^{0}\right)$ is defined in Lemma 3.

Proof. When reducing the original problem to the inverse regular and singular problems it has been shown that $v=u+w$. Thus all the conditions of Lemma 3 and Theorem 2 are fulfilled, therefore the functions $u \in C^{p+2}\left([0, T] ; U^{1}\right), q \in C^{p+2}([0, T] ; Y)$ are a solution of the regular inverse problem and the function $w \in C^{2}\left([0, T] ; U^{0}\right)$ is a solution of the singular problem. Thus there exists a unique solution of problem (1)-(3).

\section{References}

1. Zamyshlyaeva A.A. The phase space of a high order Sobolev type equation. IIGU Ser. Matemati$k a, 2011$, Vol. 4, Issue 4, pp. 45-57. (in Russ.).

2. Zamyshlyaeva A.A. The Higher-Order Sobolev-Type Models. Bulletin of the South Ural State University. Series: Mathematical Modelling, Programming and Computer Software, 2014, vol. 7, no. 2, pp. 5-28. (in Russ.). DOI: 10.14529/mmp140201

3. Zamyshlyaeva A.A. Lineynye uravneniya sobolevskogo tipa vysokogo poryadka [Sobolev type linear equations of the higher order]. Publishing Center of SUSU, 2012, 107 p. (in Russ.).

4. Abasheeva N.L. Determination of a Right-hand Side Term in an Operator-differential Equation of Mixed Type. Journal of Inverse and Ill-posed Problems, 2002, vol. 10, Issue 6, pp. 547-560. DOI: 10.1515/jiip.2002.10.6.547

5. Al Horani M., Favini A. An Identification Problem for First-order Degenerate Differential Equations. Journal of Optimization Theory and Applications, 2006, vol. 130, no. 1, pp.41-60. DOI: 10.1007/s10957-006-9083-y

6. Kozhanov A.I. Composite Type Equations and Inverse Problem. Utrecht: VSP, 1999, 171 p.

7. Fedorov V.E., Urazaeva A.V. Lineynaya evolyutsionnaya obratnaya zadacha dlya uravneniy sobolevskogo tipa [Linear Inverse Evolution Problems for Sobolev Type]. Neklassicheskie uravneniya matematicheskoy fiziki: sb. nauch. tr. [Non-classical equations of mathematical physics: collection of scientific papers], 2010, pp. 293-310. (in Russ.).

8. Sviridyuk G.A., Vakarina O.V. Cauchy Problem for a Class of Higher-Order Linear Equations Of Sobolev Type. Differential Equations, 1997, vol. 33, no. 10, p. 1418.

9. Pyatkov S.G. On some inverse problems for elliptic equations and systems. Journal of Applied and Industrial Mathematics, 2011, Vol. 5, Issue 3, pp. 417-430. DOI: 10.1134/S199047891103015X

10. Mel'nikova I.V., Filinkov A.I. Integrated semigroups andC-semigroups. Well-posedness and regularization of differential-operator problems Russian Mathematical Surveys, 1994, vol. 49, no. 6, pp. 115. (in Russ.). DOI: 10.1070/RM1994v049n06ABEH002449

11. Prilepko, A.I., Orlovsky, D.G., Vasin, I.A., Methods for Solving Inverse Problems in Mathematical Physics, New York: Marcel Dekker, 2000, 709 p.

Received June 6, 2016 
Bulletin of the South Ural State University

Series "Mathematics. Mechanics. Physics" 2016, vol. 8, no. 3, pp. 5-12

DOI: $10.14529 / \mathrm{mmph} 160301$

\title{
ОБРАТНАЯ ЗАДАЧА ДЛЯ УРАВНЕНИЯ СОБОЛЕВСКОГО ТИПА ВТОРОГО ПОРЯДКА
}

\author{
А.А. Замышляева, А.С. Муравьев \\ Южно-Уральский государственный университет, г. Челябинск, Российская Федерация \\ E-mail: zamyshliaevaaa@susu.ru
}

Исследована обратная задача для уравнения соболевского типа второго порядка в банаховом пространстве. Введение содержит постановку задачи и историографию уравнений соболевского типа. Вторая часть включает в себя предварительные сведения, основанные на результатах теории уравнений соболевского типа высокого порядка. В третьей части исходная задача редуцирована к обратной регулярной и сингулярной задачам, сформулирована и доказана теорема об однозначной разрешимости регулярной задачи. Пользуясь результатами, полученными в третьей части, в четвертой части получено решение для сингулярной задачи. Сумма решений регулярной и сингулярной является решением исходной задачи, таким образом, в работе сформулирована и доказана теорема об однозначной разрешимости обратной задачи для уравнения соболевского типа второго порядка.

Ключевые слова: уравнение соболевского типа; уравнение второго порядка; обратная задача; теорема об однозначной разрешимости.

\section{Литература}

1. Замышляева, А.А. Фазовое пространство уравнения соболевского типа высокого порядка / А.А. Замышляева // Известия Иркутского Государственного Университета. Серия: Математика. 2011. - T. 4. - Вып. 4. - С. 45-57.

2. Замышляева, А.А. Математические модели соболевского типа высокого порядка/ А.А. Замышляева // Вестник ЮурГУ. Серия «Математическое моделирование и программирование». - 2014. - Т. 7, № 2. - С. 5-28.

3. Замышляева, А.А. Линейные уравнения соболевского типа высокого порядка/ А.А Замышляева. - Челябинск: Издательский центр ЮУрГУ. - 2012. - 107 с.

4. Abasheeva, N.L. Determination of a Right-hand Side Term in an Operator-differential Equation of Mixed Type / N.L. Abasheeva // Journal of Inverse and Ill-posed Problems. - 2002. - V. 10, Вып. 6. - P. 547-560.

5. Al Horani, M. An Identification Problem for First-order Degenerate Differential Equations / M. Al Horani, A. Favini // Journal of Optimization Theory and Applications. - 2006. - V. 130, № 1. P. 41-60.

6. Kozhanov, A.I. Composite Type Equations and Inverse Problem/ A.I. Kozhanov. - Utrecht: VSP, 1999. - $171 \mathrm{c}$.

7. Федоров, В.Е. Линейная эволюционная обратная задача для уравнений соболевского типа / В.Е. Федоров, А.В. Уразаева // Неклассические уравнения математической физики: сб. науч. тр. Новосибирск, 2010. - С. 293-310.

8. Свиридюк, Г.А. Задача Коши для линейных уравнений типа Соболева высокого порядка / Г.А. Свиридюк, О.В. Вакарина // Дифференц. уравнения. - 1997. - Т. 33, № 10. - С. 1410-1418.

9. Пятков, С.Г. О некоторых обратных задачах для эллиптических уравнений и систем/ С.Г. Пятков // Сиб. журн. индустр. матем. - 2010. - Т. 13, № 4 (44). - С. 83-96.

10. Мельникова, И.В. Интегрированные полугруппы и С-полугруппы. Корректность и регуляризация дифференциально-операторных задач / И.В. Мельникова, А.И. Филинков // Успехи матем. наук. - 1994. - Т. 49, № 6(300). - С. 111-150.

11. Prilepko, A.I. Methods for Solving Inverse Problems in Mathematical Physics / A.I. Prilepko, D.G. Orlovsky, I.A. Vasin. - New York: Marcel Dekker, 2000. - 709 p.

Поступила в редакцию 6 июня 2016 г. 